\title{
COMO O FAZER PSICANALITICO PODE COLABORAR NA ANAMNESE E NA ESCUTA QUALIFICADA PRECONIZADA PELO SISTEMA ÚNICO DE SAÚDE- SUS
}

\author{
Jailton José da Silva ${ }^{1}$
}

RESUMO: Pretende-se discutir com essa pesquisa teórica, como utilizar os saberes da prática em psicanálise no serviço de saúde pública, com a intenção de encontrar meios que amenizem as reclamações direcionadas ao atendimento nesse segmento. Para tanto, buscou-se pensamentos de autores que valorizam em suas obras as variantes que permeiam o relacionamento humano. Entre as citações, algumas ideias de Freud, do sociólogo Emile Durkheim, o Psiquiatra Paulo Amarante, também do Dr. Joel Renó, da Dra. Maurano e outros, tão importantes quanto. Também foram utilizados documentos orientadores do SUS, como algumas edições da Cartilha Humaniza SUS. Esse artigo buscou entender pelo olhar dos autores pesquisados, o que aproxima e o que afasta a práxis da psicanálise da praticada no acolhimento dos serviços de saúde assistencial e de Vigilância de saúde pública. Utilizou-se a definição de saúde/doença da OMS (Organização Mundial da Saúde), a qual é corroborada pelos profissionais citados. Os autores salientaram a importância da boa oitiva, tanto para aqueles que procuram os serviços, como para os envolvidos no recebimento das demandas. Enfatizou-se o quanto funcionários e utentes estão sujeitos aos facilitadores de patologias, que induzem a diagnósticos precoces e causam divergências entre usuários e colaboradores do SUS.A pesquisa respondeu positivamente, demonstrando que o aprendizado, voltado para futuros psicanalistas, tem ferramentas capazes de colaborar no entendimento entre trabalhadores (pares e hierárquicos), e influenciar na forma como os clientes analisam os atendimentos, pois ambos, SUS e Psicanálise, partem do pressuposto que todo segredo está no aprender a escutar. Entretanto, esse artigo não abrange a todas as nuances que o assunto pode apresentar.

Palavras-chaves: Acolhimento. Escuta Qualificada. Saúde Pública

\section{INTRODUÇÃO}

O objetivo geral nesse artigo será salientar a ideia de escuta dos autores e a prática da oitiva no Serviço público de Saúde, evidenciando a resposta para a questão: Como o fazer psicanalítico pode colaborar na anamnese e na escuta qualificada preconizada pelo Sistema de Saúde brasileiro?

\footnotetext{
IServidor público - SMS - São PauloLicenciatura em Sociologia - UNIP - Universidade Paulista. Curso Superior de Tecnologias em Gestão Ambiental pela Universidade Cidade de São Paulo- UNICID. Pósgraduação Latu sensu em psicanálise-Faculdade Famart.E-mail jzoonoses@bol.com.br
} 
É extensa a lista de demandas, às quais o plano de saúde brasileiro precisa dar respostas, mas na contramão da história, percebe-se às vezes, um aumento nas reclamações dos clientes, sejam aquelas fomentadas por ideologias, ou as reais.

Dentre os protestos, os mais contundentes são relacionados à falta de empatia por parte dos servidores em geral, por esse motivo o presente artigo não pretende uma pesquisa sobre a qualidade de todos os serviços, mas focar no relacionado ao acolhimento/escuta.

São diversas as ocasiões em que são publicadas notícias de agressões entre servidores e pacientes, como o caso de Rondônia trazido a público pelo Gi por Jheniffer Núbia, gi RO (20/10/2021 13ho8) relatando que paciente quebrou computador e agrediu profissionais no Hospital João Paulo II - https://gi.globo.com/ro/rondonia/.

No Ambiente de saúde, a violência não se restringe apenas a descontroles de usuários, mas existem publicações que indicam tais ações também por parte dos cuidadores, como é o caso do enfermeiro da Cidade de Londrina, o qual foi filmado agredindo a um paciente, batendo sua cabeça na parede, conforme foi noticiado pelo jornal a folha de São Paulo, por Katna Baran, (edição de 19/o8/2019). https://wwwi.folha.uol.com.br/cotidiano

Este trabalho de curso, ápice do Curso de Pós-Graduação em Psicanálise, pretende por uma pesquisa teórica, refletir e buscar uma forma de amenizar a situação através do aprendizado próprio da psicanálise, acreditando que, se adaptados ao atendimento assistencial e de vigilância de saúde, ter-se-á como consequência mais um elemento agregador na qualificação dos trabalhadores da saúde, sem a pretensão de torná-los psicanalistas e, principalmente, melhorar a avaliação no quesito acolhimento.

Pretende-se nesse artigo expor pensamentos sobre a práxis psicanalítica, para que, quando comparados às diretrizes do Plano de Saúde Pública, tragam a luz pontos comuns, inclusive, como esse fazer pode colaborar na anamnese e na escuta do utente.

As literaturas, entrevistas e citações aqui utilizadas, são de autores comprometidos com o avanço da psicologia que, através de seus pensares, apresentarão qualidades da psicanálise aproveitáveis no labor dos servidores da assistência e da Vigilância de Saúde. 
Estudiosos como o psiquiatra e escritor Paulo Amarante, autor do livro "Saúde Mental e Atenção Psicossocial”, Joel Rennó - PhD em Ciências, professor colaborador médico do Departamento de Psiquiatria da FMUSP, Dr. Sigmund Freud, a professora e psicanalista Denise Maurano e documentos orientadores do SUS, dentre outros autores, ajudarão a entender a importância da boa escuta, ou até dar um novo sentido ao termo: 'escuta qualificada', tão discutido entre os gestores da Saúde Pública.

A importância desse artigo para o segmento acadêmico será pautada no atual contexto social, onde, um número significativo de literaturas, já apontam para um aumento de casos diagnosticados como distúrbios mentais, elementos que influenciam na demanda assistencial de saúde, o que dá a essa abordagem a chance de somar-se àquelas, ampliando o olhar para o acolhimento, porta de entrada para todos os serviços do SUS.

\section{DESENVOLVIMENTO}

A história está saindo de um momento que parecia ser eterno, onde lepra e distúrbio mental eram tratados da mesma forma e exclusão era a palavra de ordem, para inserir-se no movimento que tem como base a clínica ampliada, a qual aprecia a participação e a valorização de tudo que está ao redor do paciente.

Como enuncia o texto da psicóloga CUNHA, et al, (2017) Acompanhamento Terapêutico: Concepções e Possibilidades em Serviços de Saúde Mental:

O dia a dia, o contexto familiar, social, o lazer visto de dentro da realidade
cotidiana vivenciada nos atendimentos sinalizarão os caminhos a serem
percorridos, os objetivos a serem traçados e o término do trabalho,
constituindo um impulso para a reconstrução de uma autonomia de base e
para a plena utilização dos recursos e potenciais disponíveis no cotidiano do
paciente. [...]". CUNHA, et al, (2017 v. 37 n.30)

Esta mesma ideia também foi encontrada no texto de FERRO, (2018), et al: Acompanhamento terapêutico em saúde mental: estrutura, possibilidades e desafios para a prática no SUS. FERRO, Luis Felipe - (Goiânia, v. 24, n. I, p. 66-74, 2018).

Descobrir o sofrimento não pela vida acadêmica dos médicos, mas pela fala, pela escuta do sofredor, valorizar sua vida, seus costumes, sua rede social, ajudá-lo a redescobrir-se, para então empoderá-lo e permitir a este o retorno e a participação na 
identificação do elemento que o retira do controle de sua própria vida, é o objetivo maior do tratamento terapêutico, da clínica ampliada, do movimento antimanicomial. (Humaniza SUS Série B. Textos Básicos de Saúde Brasília - DF 20ı0).

Conforme a Cartilha do PNH - Plano Nacional de Humanização, o advento de novos pensares permite, não só um recrudescimento na forma de ver saúde mental, mas, vai além das fronteiras sobre saúde e conduzirá a uma introspecção sobre como usamos o termo respeito e atenção ao outro.

Todos os serviços sociais começam a partir de uma entrevista, seja para saber o que o outro quer, ou o que está passando, mas todas se deparam com o fator humano, a subjetividade, elemento capaz de causar tanto divergências, como convergências.

Isso tem muito a ver com o fazer da psicanálise, mas também com a busca do SUS por excelência em acolhimento, também discutida no Trabalho de Pósgraduação de SANTOS, "O trabalho de escuta qualificada trata da relação entre pessoas, que se aprofunda na medida em que trata do interesse de um pelo outro, não é só o ouvir, mas o escutar.” SANTOS, J. S. (2014) TC - MBA em Gestão de Pessoas da PósGraduação lato sensu, do Programa FGV in company.

Essa 'escuta' no serviço assistencial e na vigilância de saúde recebe o nome de anamnese, a qual é definida no site Anamnese/SIMIOLOGIA UFOP da Universidade Federal de Ouro Preto como: "O roteiro da anamnese é uma forma padronizada de registrar a entrevista. Para a realização de uma boa anamnese, acima de tudo é necessário saber ouvir." https://semiologiamedica.ufop.br/anamneseEntretanto é notório que a cada dia encurta-se mais e mais o tempo de escuta.

Esse momento deveria deixar transparecer: porque sofre, quanto sofre, e permitir, tanto a quem ouve, como a quem fala identificar o gatilho que detona a crise.

A ação dessa ferramenta na atenção médica, não possui a mesma eficácia vista no atendimento psicanalítico, talvez porque no atendimento assistencial, buscam por sinais de patologias, baseiam-se em perguntas, enquanto na psicanálise freudiana, a busca será por um auto-reconhecimento e, só em algumas situações, existirá a nomeação de sofrimentos, entretanto, será sempre viabilizada por uma associação livre. 
FOCHESATTO, Mestre em saúde pela PUCRS, em seu artigo “A cura pela fala”, cita o pensamento freudiano: “[...] Quem tem olhos para ver e ouvidos para ouvir fica convencido de que os mortais não conseguem guardar nenhum segredo" (Ibidem, p.78 caso Dora). [...] Freud, apud Waleska P. F. Fochesatto, (2009)

Esse primeiro contato é de alta relevância para atendentes e atendidos, pois, cria laços empáticos, os quais, conforme a qualidade do atendimento, irão refletir como positivos ou negativos em situações posteriores que ocorrerão entre paciente e cuidador.

A Revista Brasileira de Educação Médica, (2019), no artigo: "Ensinando a Anamnese Psiquiátrica para Estudantes de Medicina através da Inversão de Papéis: Relato de Experiência" instrui:

[...] é considerada um dos pilares da boa prática médica 2-4. A empatia é um conceito complexo e multidimensional, que engloba aspectos morais, cognitivos, emocionais e comportamentais, sendo um componente essencial de todos os relacionamentos construtivos 2,3,5. O domínio cognitivo da empatia se refere à capacidade de entender as experiências subjetivas e aos sentimentos de outra pessoa e de ver o mundo pela perspectiva dela, enquanto o domínio afetivo envolve a capacidade de compartilhar as experiências e sentimentos do outro.” TORRES, Albina Rodrigues - Revista Brasileira de Educação Médica [online]. 2019, v. 43, n. 2

Segundo AMARANTE a conceituação de loucura é polissêmica, essa ideia

pode ser justificada pela própria polifonia formadora de todo ser. A palavra loucura é constructo social, cada ser reproduz para esse termo e para outros, significados intimamente ligados à sua formação, que tanto podem ser alimentados por uma imposição, como movidos por uma pseudo-originalidade.

[...] De acordo com BURR (1998), o ser humano é socialmente construído através de interações e produto de discursos cultural e historicamente contingentes. [...] segundo GERGEN (1999), a perspectiva do Construcionismo Social veio ampliar e fornecer novos elementos para uma interpretação diferenciada do fenômeno "doença mental", que destrói aquelas premissas rígidas e alheias ao contexto social, sob o argumento de que uma postura "neutra" e "imparcial" não está isenta de influências morais e políticas." VASCONCELOS, et al (2010).

A interpretação da loucura sem ideias preconcebidas é sempre um desafio para qualquer humano dito hígido, visto que são frutos do meio e não sabem ao certo de que lado estão, além de estar sempre divididos, entre os que quebram as regras e aqueles que as reproduzem sem questionamentos.

Segundo FREUD, as normas éticas conciliariam as vontades dos "IDs", socializando, ou seja, o superego colocaria um limite nas exigências do ID: "O limite do 
aceitável pela sociedade”. Nessa linha de Pensamento está o Sociólogo DURKHEIM, (1858/1917), apud MELLO, (2015), portal educação, apresenta a sociedade como exterior e anterior ao sujeito, então, será que tantas pressões para controlar e/ou para adaptar poderiam provocar uma perda da naturalidade, ou uma fuga?

$\mathrm{O}$ artigo de VASCONCELOS, et al, (2010), expõe o seguinte: "Dessa forma, devemos olhar para o processo saúde/doença como derivado de vários fatores que se produzem historicamente, que são expressões da totalidade de relações vividas pelo indivíduo, ou seja, o processo saúde/doença não é mera expressão ou atualização do plano biológico."

Embora haja quem discorde, não seria essa ideia plausível, à luz da possibilidade de sofrimentos causados por pressões sociais sobre gerações? Marcas não seriam impressas a ponto de se tornarem traços genéticos?

O Dr. SETÚBAL, (2015), no artigo "Herdando Transtornos Mentais" traz a ideia que: "Os transtornos mentais são o resultado de fatores genéticos e ambientais. Não há interruptor genético único que, quando aparece, causa um transtorno mental [...]”. José Luiz Setúbal. Todavia, na continuação desse mesmo texto, afirma ser difícil para a medicina conceber que tal dano tenha sido hereditário.

JR, (2020), PhD em Ciências e diretor do Programa de Saúde Mental da Mulher do Instituto de Psiquiatria da USP (IPq-USP), cita uma pesquisa com jovens e adolescentes focando o desenvolvimento de depressão e transtornos do uso de álcool, com classes sociais diferentes e conclui da seguinte forma:

Portanto, pelos dados desse importante trabalho chegamos à conclusão de que as adversidades ambientais podem levar a modificações genéticas definitivas que causam depressão em nossos filhos adolescentes. Essas adversidades incluem status socioeconômico baixo por culpa de governos corruptos e omissos em políticas sociais, também por ambientes familiares repletos de conflitos. O comportamento doentio de seu filho pode ser produto do meio e hoje a biologia explica essa relação de forma consistente!!”. Joel Rennó JR, (2020)

A citação acima endossa a relevância do bom acolhimento e do saber ouvir, o que vai permitir ao atendente e ao cliente, detectarem os problemas que provocam tais sintomas e proporcionar a sua não inserção no mundo da medicalização.

Digladiamo-nos entre certo e errado, doente ou saudável, louco ou lúcido. Continuamos influindo no meio e reproduzindo nossas ideias, mesmo sendo elas 
apenas concepções de grupos. Segundo AMARANTE, (2007) o termo "louco" é polissêmico e nós, produtos do meio do qual fazemos parte.

O louco é sempre o outro, todavia, não podemos deixar de notar que tudo envolvendo humanidades nos impulsiona em direção àqueles. Somos interdependentes, ninguém vai ou volta dessa viagem com mãos vazias, e nessa aventura concretiza-se a maior qualidade humana, a de simbióticos. Como já enunciou Aristóteles: "O homem é um ser social porque é um animal que precisa dos outros membros da espécie”. (Site: apeiron. webnode)

Com o advento do SUS e do movimento antimanicomial, somos impulsionados a pensar que, para lidar com saúde, precisamos estar dispostos a nos livrar de amarras e, uma vez libertos, partir em direção ao desvendar o outro, sem ideias pré-concebidas, mas abertos para novas possibilidades, inclusive a de conceber que saúde pode ser um estado de espírito.

A OMS (Organização Mundial de Saúde), define saúde como: "Um estado de completo bem-estar físico, mental e social e não apenas como a ausência de infecções ou enfermidades”. Mas, como diagnosticar os fatores prejudiciais à saúde sem a escuta adequada e ou com a visão voltada à medicalização?

Seguindo o pensamento do Psiquiatra AMARANTE, quanto à concepção do cuidado na saúde mental, não é difícil neste brainstorming perceber o quanto estamos longe de adquirir um rumo, mas também é perceptível o quanto os sentimentos de intolerância, moralismos e verdades únicas nos afastam do caminho.

FREUD, apud JOÃO, (2015), em: “Alguns aspectos da Mente Humana” entende, que: "O ser humano não é movido apenas por sua parte consciente, grande parte das ações humanas é muito influenciada por uma porção da psiquê que não é plenamente percebida pela nossa consciência." Mas também por uma parte obscura, segundo ele "composta pelos nossos instintos, desejos, medos e lembranças que foram rechaçados pela porção consciente da nossa psiquê em virtude de regras morais”. apud A. A. JO ÃO (p. 5. I를 Edção)

Diante disso pode-se assentir ao pensamento de que “[...] Qualquer espécie de categorização é acompanhada do risco de um reducionismo e de um achatamento das possibilidades da existência humana e social”. AMARANTE (2007)

Depreende-se conforme citação anterior do livro “Alguns Aspectos Da Mente Humana" que, diante de um quadro de análise de sofrimento mental, teremos o 
encontro de envolvidos influenciados pelo meio, pela cultura, pela classe social, dentre outros. Isso sincronicamente.

São muitos os trabalhadores da saúde que colaboram com a ampliação do número de pessoas afastadas de suas atividades laborais e incluídas na vida medicamentosa, por vezes, vitimados por pressões e pela ausência de ouvidos capazes de escutar, todavia, ávidos por falar, mas obrigados a ouvir. Fatos que aumentam as discussões em torno das Síndromes, dentre elas a síndrome de Burnout.

Conforme o artigo "Síndrome de Burnout", veiculado pela Revista Brasileira de Medicina do Trabalho (V. I4 N.2-2016):

\begin{abstract}
Burnout. [...] É um problema que atinge profissionais de serviço, principalmente os cuidadores, em que a oferta do cuidado ou serviço frequentemente ocorre em situações de mudanças emocionais. A Síndrome de Burnout (SB) assume uma concepção multidimensional, cuja manifestação se caracteriza por esgotamento emocional, redução da realização pessoal no trabalho e despersonalização do profissional. F. P. L. e PÊGO'/D. R. PÊGO ${ }^{2}$
\end{abstract}

Todos sofrem as consequências da exacerbação dessas influências, enquanto diagnosticados, ou diagnosticando, independente do seu status, encontram-se sob o jugo dos mesmos influenciadores. Influenciados inconscientes tornam-se faladores, o que destoa tanto da escuta qualificada preconizada pelo SUS, como da prática psicanalítica. Descaracteriza também a função da entrevista ou anamnese.

A psicóloga pela Universidade Federal de Juiz de Fora (2000), especialista em Psicanálise e Saúde Mental, mestra em Psicanálise pela (UERJ) Universidade do Estado do Rio de Janeiro (2002 e 2007), Lavinia C. BRITO, discute a psicanálise nas salas de aula das faculdades e a divergência entre suas essências, pois, na sala a fala é do professor e ao aluno cabe ouvir, divergindo do fazer na psicanálise, local onde o anfitrião se cala para aguçar sua audição.

Essa última situação é semelhante ao que prega o SUS, mas reconhece na apresentação da Cartilha da PNH / 2007 [...] "Uma prática muito comum nos serviços de saúde é justamente a redução dos usuários a um recorte diagnóstico ou burocrático (o diabético, o alcoolista ou, pior ainda, o leito número tal [...]" Cartilha da $\mathrm{PNH} 2^{\underline{a}}$ edição Serie B “Textos Básicos da Saúde” - Brasília Distrito Federal/2007

$\mathrm{Na}$ Dissertação apresentada a Universidade do Estado do Rio de Janeiro para obtenção do Título de Mestre em Psicanálise, BRITO cita: [...] “A desidealização 
desta posição: lugar de "cala" e não de fala, de abstinência e não de gozo, enfim, lugar de objeto e não de sujeito”. L. C. BRITO/2007 (A Formação Psicanalítica p.5o).

Essa desidealização cabe inteiramente no atendimento assistencial de saúde pública, pois o Sistema de Saúde brasileiro tem suas diretrizes voltadas ao ouvir, entretanto, também pode significar um desafio, visto que, sua práxis incorporou a fala, em detrimento da escuta.

O texto de BRITO, (2007), corrobora com MACEDO e FALCÃO, (2004), que também discute no artigo "A escuta na psicanálise e a psicanálise da escuta", o encontro entre psicanalista e paciente, momentos também vivenciados pelo servidor do SUS em sua vida laboral: [...] "Esses tempos em Freud inauguraram a singularidade de uma situação de comunicação entre paciente e analista. Um chega com palavras que demandam um desejo de ser compreendido em sua dor, o outro escuta as palavras por ver nestas as vias de acesso ao desconhecido que habita o paciente[...]" Psychê Revista de Psicanálise (Psychê, vol.IX, núm. 15, 2005, pp. 65-76)

Os territórios de saúde são servidos por serviços de atenção com atuação diferenciadas, Vigilância Ambiental, Vigilância Epidemiológica, Saúde da família e outros, mas todos possuem como base de atendimento o diálogo com os munícipes e são totalmente dependentes da concepção de uma boa escuta.

Considerando os pensamentos já citados, depreende-se que na formação do psicanalista, a autoanálise é fator preponderante, entretanto, o servidor da saúde que lida em seu cotidiano com questões similares às enfrentadas por aqueles, está exposto, sendo obrigado a cuidar e, às vezes, aconselhar a problemas pelos quais pode estar sendo vitima, mas ainda não os reconhece em si mesmo. Esta situação pode causar impressão negativa sobre a instituição, também sobre o colaborador.

Continuando o raciocínio sobre a neutralidade e o respeito que se deve expressar numa escuta, LAING, apud P. AMARANTE, (20II, p.I6) traz a ideia que: "a forma inicial de ver uma coisa determina todas as nossas relações subsequentes com ela."

Pessoas já foram internadas em manicômios e esquecidas como loucas, isso apenas por não aceitarem a opressão dos padrões vigentes, demonstrando que, também o cuidado está sujeito às relatividades impostas por um sistema que protege e acusa simultaneamente. 
O SUS, em suas diretrizes, preconiza que um cidadão deve ser visto de forma integral, ou seja, o atendente/sistema deve ter uma visão holística, então, diante de tal fato, a psicanálise, a qual ensina a prática do silêncio, pode contribuir para que a oitiva seja um meio de reconhecimento, mas, além disso, uma forma de entrosamento simbiótico, visto que um lado precisa falar e o outro ouvir, isso para angariar informações e intervir, ou não. Tanto utente, quanto cuidador!

Conforme a fala de SOUZA, et al, (2012,) em 'Integralidade na atenção à saúde: um olhar da Equipe de Saúde da Família sobre a fisioterapia': "Integralidade enquanto princípio do Sistema Único de Saúde busca garantir ao indivíduo uma assistência à saúde que transcenda a prática curativa, contemplando o indivíduo em todos os níveis de atenção e considerando o sujeito inserido em um contexto social, familiar e cultural”

Sabe-se que em diversas situações, o servidor da saúde vai além de uma simples anamnese, porém, não podemos deixar de salientar a diferença entre um e outro (anamnese/entrevista), todavia, é necessário entender o quanto pode ser absorvido de características do fazer psicoterapêutico, pelo fazer do servidor do SUS, apenas para melhor qualificá-lo, por exigência da própria função.

O texto "O psicodiagnóstico entre as incompatibilidades de seus instrumentos e as promessas de uma metodologia psicopatológica” discute as divergências nas ferramentas introdutórias de intervenção em saúde, aonde conforme os doutores em psicopatologias, psicólogos e psicanalistas pela Université Paris VII: “ $\mathrm{Na}$ anamnese a preocupação e a finalidade residem na compilação de dados, e o paciente fica reduzido a um mediador entre sua enfermidade, sua vida e seus dados, por um lado e o médico por outro". JUNIOR e FERRAZ (200I).

Essa mesma obra ainda argumenta sobre esses instrumentos de acolhimento apontando o que os difere: “[...] diferença da entrevista e da anamnese é que a segunda trabalha a partir da suposição que o paciente conhece sua vida e que está para fornecer dados sobre a mesma. A suposição da entrevista é que o sujeito, sem sabê-lo de modo consciente, organiza uma história de vida e um esquema do seu presente. [...]" JUNIOR e FERRAZ (200I).

A Psicóloga, Psicanalista, mestra em Filosofia e professora associada da Universidade Federal do Estado do Rio de Janeiro, MAURANO, (2010), em sua obra "Para que serve a psicanálise”, retrata a prática psicanalítica como: 
[...] Considerando que o verbo “servir", situado no centro da questão título, é proveniente etimologicamente de trabalhar como servo, eu diria que a psicanálise é sobretudo serva de sua ética. Isso porque, se em termos operativos a psicanálise serve a uma infinidade de possibilidades de intervenções, dado que seu campo de ação é vastíssimo e a cada dia amplia-se ainda mais...” Denise Maurano (2010).

\section{CONSIDERAÇÕES FINAIS}

A Proposta desse artigo é responder ao questionamento: Como o fazer psicanalítico pode colaborar na anamnese e na escuta qualificada preconizada pelo Sistema Único de Saúde brasileiro?

Esse plano de saúde lida e é influenciado por muitas demandas, além de ser limitado por questões políticas, quando seus limites são geridos por decisões legislativas ou administrativas, todavia, a questão que mais atrai a opinião pública é a do acolhimento. Os clientes têm pouco acesso às informações que norteiam a execução dos serviços, então, entram em choque o direito e o dever, que também atua em ambos os lados.

Cabe tanto ao cliente, como ao representante do sistema, obedecer às regras, mas ambos são influenciados pelos agentes sócio econômicos, culturais e ambientais, os quais geram patologias por vezes mascaradas por ideologias, preconceitos, e pseudo sabedorias, mas, também por sofrimentos ainda não autoconhecidos nos e pelos sujeitos.

O trabalhador da saúde pode ser vitima tanto de ataques por insatisfação, como por um sistema que o coloca, sem preparo psicológico, para lidar com problemas que muitas vezes também o atinge. Esta situação prejudica tanto ao cuidador como ao utente, sem falar no desgaste à imagem do plano de saúde.

Percebe-se que a ação psicanalítica e a teoria do SUS, possuem elementos afins, clamam por momentos de escuta bem feita, já que o acolhimento, segundo os pensadores, deve ser baseado na participação ativa do suposto sofredor, teoricamente o mesmo buscado pelo Sistema de Saúde, entretanto, para esse último, chega a ser um desafio, pois, embora solícito por uma escuta qualificada, em sua práxis, incorpora a fala.

Para tal, sugeri-se que sejam inseridas disciplinas constantes da formação psicanalista, sem pretender tal status para o colaborador da saúde. Envolvendo a todos 
do atendimento, mas também aos gestores, os quais precisam despertar para as demandas que permeiam o mundo dos envolvidos (as) diretamente no atendimento da saúde da população.

Pode-se esperar como resultado um público usuário, satisfeito pela escuta e, um servidor da saúde mais preparado para ouvir. Entretanto, existem outras demandas que serão inseridas nessa questão, as quais esse trabalho não se propôs a descrevê-las.

Como contra ponto nessa pesquisa, percebeu-se que os resultados deixam a desejar no que se refere a como aplicar e, também não levou em conta a visão do funcionário em relação ao seu próprio fazer, isso porque a proposta seria um estudo teórico sobre as qualidades aproveitáveis ao SUS do exercício de escuta característico do fazer do psicanalista.

Essa é uma questão que não se esgota em uma pesquisa bibliográfica ou teórica, faz-se necessário a ampliação de parâmetros gerais, contando com a inclusão da busca por dados quantitativos e qualitativos.

\section{REFERÊNCIAS}

AMARANTE, Paulo. - Saúde Mental e Atenção Psicossocial (3 ${ }^{\underline{a}}$ ed., editora FiocruzRio de Janeiro, 20II)

AMATNEEKS, Thais Malucelli. - A Incrível Arte de Escutar o Paciente/2or8Psiconefrologia- Fundação Pró-Renal http://psiconefrologia.com/2018/o6/2I/aincrivel-arte-de-escutar-o-paciente/

Anamnese/SIMILOGIA UFOP - https://semiologiamedica.ufop.br/anamnese-

BARAN, Katna -(Folha São Paulo, edição 19/o8/2019 - 20:56) Vídeo mostra enfermeiro agredindo paciente em unidade de saúde de Londrina - 19/08/2019 - Cotidiano - Folha (uol.com.br) acesso 07/12/2021

BARROS, - Ivan da Costa /2004, em "A Anamnese" https://www.saudedireta.com.br/docsupload/1332097453Anamnese.pdf acesso I2/09/2021

BRITO, - Lavinia (2007), A FORMAÇÃO DO PSICANALISTA- Dissertação apresentada a UERJ como requisito parcial para obtenção do Título de Mestre em Psicanálise, http://www.livrosgratis.com.br acesso em II/o9/202I

https://bvsms.saude.gov.br/bvs/publicacoes/humanizasus_documento_gestores_trabal hadores_sus.pdf acesso em I2/o9/2021 
CANCIAN, - Renato- Especial para a Página 3 Pedagogia \& Comunicação (TextoDurkheim (2) - A consciência coletiva e fatos sociais) https://educacao.uol.com.br/disciplinas/sociologia/durkheim-2-a-consciencia-coletivae-fatos-sociais.htm acesso em 26/05/2021

Cartilha da PNH - Clínica Ampliada, Equipe de Referência e Projeto Terapêutico Singular 2 $2^{\text {a }}$ edição Serie B “Textos Básicos da Saúde" - Brasília Distrito Federal/2007 OS_oo8o_M.indd (saude.gov.br) Acesso or/ro/202I

Cartilha do PNH-Plano Nacional de Humanização-"O HumanizaSUS na Atenção Básica" (Humaniza SUS I⿳亠丷厂 edição I⿳a reempressão Série B. Textos Básicos de Saúde Brasília - DF 2010) ,Humaniza SUS - Atenção Básica I.pdf (usp.br) Acesso 05/08/2021

CUNHA, Amanda Candeloro, PIO, Danielle Abdel Massih e RACCIONI, Thaís Munholi - Acompanhamento Terapêutico: Concepções e Possibilidades em Serviços de Saúde Mental. Psicologia: Ciência e Profissão [online]. 2017, v. 37, n. 3 [Acessado 26, maio, 2021], pp. 638-651. Disponível em: 〈https://doi.org/ro.1590/1982-3703000092016〉. ISSN 1982-3703. https://doi.org/ro.1590/1982-3703000092016.

http://dx.doi.org/10.18065/RAG.2018v24nI.7.

FERRO, Luis Felipe et al. Acompanhamento terapêutico em saúde mental: estrutura, possibilidades e desafios para a prática no SUS. Rev. abordagem gestalt., Goiânia, v. 24, n. I, p. 66-74, abr. 2018. Disponível em $<$ http://pepsic.bvsalud.org/scielo.php?script=sci_arttext\&pid=SI8o9-

$68672018000100008 \& \operatorname{lng}=$ pt $\& \mathrm{nrm}=$ iso $>$. acessos em I2 set. 2021.

FOCHESATTO, Waleska Pessato Farenzena. A cura pela fala. Estud. psicanal., Belo Horizonte, n. 36, p. 165-171, dez. 2011. Disponível em 〈http://pepsic.bvsalud.org/scielo.php?script= sci_arttext \& pid=Soroo-34372011000300016 $\& \operatorname{lng}=\mathrm{pt} \backslash \mathrm{nrm}=\mathrm{iso}>$. acessos em 26 maio 202I.

NUBIA, Jheniffe - $\quad$ gI $\quad$ RO https://gr.globo.com/ro/rondonia/noticia/2021/Io/20/enfermeira-leva-soco-e-tecnicatem-cabelo-arrancado-durante-ataque-de-paciente-em-hospital-de-porto-velho.ghtml Acesso 07/12/2021

JOÃO, Antonio Auggusto - Alguns Aspectos Da Mente Humana-2015 https://books.google.com.br/books? id= acesso 22/o6/2021

MACEDO, Mônica Medeiros Kother / FALCÃO, Carolina Neumann de Barros - A escuta na psicanálise e a psicanálise da escuta. Psychê [en linea]. 2005, IX (I5), 6576[fecha de Consulta 5 de Diciembre de 2021]. ISSN: 1415-1138. Disponible en: https://www.redalyc.org/articulo.oa?id=30715905

MAURANO, Denise - Para que serve a psicanálise - edição 3 Rio de Janeiro, 2010 https://filosoficabiblioteca.files.wordpress.com/2016/o3/maurano-d-pra-que-serve-apsicanczarlise.pdf acesso ro/o9/2021 
MELLO, Thiago de,- Indivíduo e a Sociedade http://educacao.globo.com/sociologia/assunto/conflitos-e-vida-emsociedade/individuo-e-sociedade.html acesso $02 / 12 / 2021$

NETTO, G.A.F- A Ética da Psicanálise https://www.associacaolivre.com.br/

SANTOS, J. P - A Escuta Qualificada- Instrumento Facilitador no Acolhimento ao Servidor Readaptado. TCC Escuta Qualificada Versao I2 (bvsalud.org) acesso em 09/09/2021

PÊGO, F. P. L/ PÊGO, D. R- https://www.psicanaliseclinica.com/acting-out/ acesso 22/06/2021

PÊGO, F. P. L./PÊGO, D. R. -Revista Brasileira de Medicina do Trabalho V. I4 N.22016 https://www.rbmt.org.br/details/46/pt-BR/sindrome-de-burnout acesso $24 / 06 / 2021$

RENNÓ, Joel - Somos frutos do meio em que vivemos? Quem explica Freud ou a Biologia https://emais.estadao.com.br/blogs/joel-renno/somos-frutos-do-meio-emque-vivemos-quem-explica-freud-ou-a-biologia/ Acesso em II/o9/202I

SETÚBAL, J. L - Herdando Transtornos Mentais https://institutopensi.org.br/ acesso $22 / 06 / 2021$

SILVA JUNIOR, Nelson da / FERRAZ, Flávio Carvalho - O psicodiagnóstico entre as incompatibilidades de seus instrumentos $e$ as promessas de uma metodologia psicopatológica. Psicologia USP [online]. 200I, v. I2, n. I [Acessado 30, agosto 2021], pp. 179-202. Disponível em: 〈https://doi.org/10.1590/Soro3-65642001000100009〉. Epub 6 Ago 2001. ISSN 1678-5177. https://doi.org/10.1590/So103-65642001000100009.

SOUZA. M. C / et al - Integralidade na Atenção à Saúde: Um Olhar da Equipe de Saúde da Família sobre a Fisioterapia - (O Mundo da Saúde - São Paulo - 2012) https://bvsms.saude.gov.br/bvs/artigos/mundo_saude/integralidade_antecao_saude_ol har_equipe.pdf acesso 21/05/2021

TORRES, Albina Rodrigues et al. Ensinando a Anamnese Psiquiátrica para Estudantes de Medicina através da Inversão de Papéis: Relato de Experiência. Revista Brasileira de Educação Médica [online]. 2019, v. 43, n. 2 [Acessado 12 setembro 2021], pp. 200-207. Disponível em: <https://doi.org/ro.1590/1981-52712015V43n2RB20180123>. ISSN 1981-527I. https://doi.org/10.1590/198I-52712015v43n2RB20180123.

VASCONCELOS, Isabel et al. Concepções de loucura em um traçado históricocultural: uma articulação com o Construcionismo. Mental, Barbacena, v. 8, n. I4, p. 4963, 2010. Disponível em <http://pepsic.bvsalud.org/scielo.php? acessos em ro abr. 202I. 